\title{
O USO DE BIODIGESTORES EM PEQUENAS E MÉDIAS PROPRIEDADES RURAIS COM ÊNFASE NA AGREGAÇÃO DE VALOR: UM ESTUDO DE CASO NA REGIÃO NOROEŞTE DO RIO GRANDE DO SUL
}

\author{
Rodrigo Barichello* \\ Ronaldo Hoffmann** \\ Suzane Orte Cardoso da Silva**: \\ Moacir Francisco Deimling** \\ Nelson Casarotto Filho******
}

RESUMO: A partir da vigência do Protocolo de Kyoto houve um interesse renovado pela tecnologia dos biodigestores. Como eles permitem uma redução na emissão de gases do efeito estufa, em relação a outros métodos de tratamento de dejetos, a sua implantação pode permitir a comercialização de créditos de carbono, resultando em valores monetários. O presente trabalho tem como objetivo analisar o processo de disseminação desta tecnologia na Microrregião de Santa Rosa, situada na Mesorregião do Noroeste riograndense, impulsionada, especialmente, por empresas privadas. O presente estudo revelou que $33,33 \%$ dos equipamentos instalados encontram-se desativados. Estudou-se o perfil das propriedades que possuem estes equipamentos instalados, além de uma análise das possíveis dificuldades encontradas pelos proprietários rurais, no sentido de implantação e utilização dessa tecnologia, verificando-se a contribuição dos biodigestores, referente à questão energética e minimização da poluição do meio ambiente nessas áreas. Através da revisão da literatura existente e aplicação de questionários, foram levantadas diversas informações acerca da instalação de biodigestores, observando se contribuem como alternativa de agregação de valor às propriedades criadoras e como alternativa viável para a solução dos problemas ambientais envolvidos no processo.

PALAVRAS-CHAVE: Biodigestores Aplicados à Suinocultura; Biogás na Geração de Energia Elétrica; MDL e Suinocultura.

\footnotetext{
Doutorando em Engenharia de Produção pela Universidade Federal de Santa Catariana; Docente Titular da Área de Ciências Sociais e Aplicadas da Universidade Comunitária da Região de Chapecó (UNOCHAPECO)

${ }^{* *}$ Doutor em Engenharia Mecânica pela Universidade Federal do Rio Grande do Sul (UFRGS); Docente Titular da Universidade Federal de Santa Maria (UFSM)

*** Graduanda em Administração; Bolsista da Modalidade Iniciação Científica, do Fundo de Apoio à Pesquisa da Unochapecó (PIBIC/FAPE); E-mail: suorte@gmail.com

***** Doutor em Engenharia de Produção (PPGEP/UFRGS); Docente da Universidade Federal da Fronteira Sul

****** Doutor em Engenharia de Produção pela Universidade Federal de Santa Catarina (UFSC); Docente Associado (estatutário) da Universidade Federal de Santa Catarina (UFSC)
} 


\section{BIODIGESTERS IN SMALL- AND MIDDLE-SIZED FARMS, WITH SPECIAL EMPHASIS ON VALUE AGGREGATION: A CASE STUDY IN THE NORTHWESTERN REGION OF THE STATE OF RIO GRANDE DO SUL, BRAZIL}

ABSTRACT: The Kyoto Protocol has triggered an interest for the technology of biodigesters. Since they reduce the emission of greenhouse gases when compared to other methods for the treatment of wastes, their establishment permits the commercialization of carbon credits and consequently financial assets. Current paper analyzes the dissemination process of the technology in the micro-region of Santa Rosa in the mesoregion of the northwestern of the state of Rio Grande do Sul, Brazil, mainly triggered by private enterprises. The study showed that $33.33 \%$ of equipments ceased to work. The profile of farms with equipments and their possible difficulties with regard to the establishment and use of the technology have been assessed. The contribution by biodigesters with regard to the energy problem and the decrease of pollution in the environment in the region has been evaluated. A review of the literature and questionnaires revealed data on the installation of biodigesters on whether they contributed as an alternative of value aggregation to the farms and a viable alternative towards the solution of environmental issues involved in the process.

KEY WORDS: Biodigesters in Swine Breeding; Biogas in the Generation of Electric Energy; MDL and Swine Breeding.

\section{INTRODUÇÃO}

A redução do impacto das atividades econômicas sobre o meio ambiente é uma realidade atual, e deixou de ser um assunto somente para ecologistas. Nesta concepção, a atividade da suinocultura vem apresentando significativo crescimento, o que traz consigo uma grande preocupação quanto à degradação ambiental e, consequentemente, prejuízos à qualidade de vida das pessoas.

Com o aumento da produção, cresce a geração de dejetos. Como consequência, a atividade da suinocultura, devido aos excrementos gerados pelos suínos (dejetos), é considerada uma "atividade potencialmente causadora de degradação ambiental” (EPAGRI, 1995; EMBRAPA, 1995; HOLM-NIELSEN; AL SEADI; OLESKOWICZ-POPIEL, 2009). 
A tecnificação para o tratamento dos dejetos suínos é o grande desafio para a sustentabilidade dessa atividade. É necessário evitar que um volume tão grande de dejetos continue a ser lançado no meio ambiente, poluindo mananciais, solo, ar, pois comprometem não somente a qualidade de vida das populações rurais e urbanas, como também a sobrevivência da fauna e da flora das regiões onde os criatórios estão inseridos.

A tecnologia da digestão anaeróbica em biodigestores é uma das possibilidades para o combate da poluição gerada por esta atividade e que, ao mesmo tempo, agrega valor às propriedades rurais. A utilização de biodigestores tem merecido importante destaque devido aos aspectos de saneamento e energia, além de estimular a reciclagem de nutrientes (BARICHELLO; HOFFMANN, 2010).

A digestão anaeróbica do resíduo animal através do biodigestor resulta na produção de biogás, composto basicamente por metano $\left(\mathrm{CH}_{4}-60\right.$ a 70\%) e dióxido de carbono $\left(\mathrm{CO}_{2}-30 \%\right)$. Nos últimos anos houve o ressurgimento do interesse na captura de biogás, devido à crescente preocupação com o aquecimento global. $\mathrm{O}$ aproveitamento do biogás para geração de energia elétrica ocasiona uma redução no potencial de poluição do meio ambiente, uma vez que é queimada a mistura composta por acentuada concentração de gás metano $\left(\mathrm{CH}_{4}\right)$, cerca de vinte (20) vezes mais poluentes que o dióxido de carbono $\left(\mathrm{CO}_{2}\right)$, no que se refere ao efeito estufa (OLIVEIRA, 2004; ABBASI; TAUSEEF; ABBASI, 2012).

$O$ item energia é cada vez mais evidenciado pela interferência no custo final de produção: no caso da suinocultura, é um fator que merece ser bem trabalhado, uma vez que as oscilações de preço do produto reduzem a competitividade do setor. $O$ aproveitamento energético do biogás objetiva a melhoria do desempenho global do tratamento do dejeto suíno, reduzindo a emissão de gases do efeito estufa, colaborando para aumentar a eficiência energética da propriedade rural e, consequentemente, a sustentabilidade da produção.

Neste contexto, este artigo apresenta o estudo de caso do processo de disseminação desta tecnologia na Microrregião de Santa Rosa, situada na Mesorregião do Noroeste riograndense, impulsionada, especialmente, por empresas privadas. 


\section{REVISÃO BIBLIOGRÁFICA}

\subsection{GERAÇÃO DE BIOGÁS NA SUINOCULTURA: BIODIGESTOR}

O Brasil é dono de uma das biomassas mais exuberantes e de um dos maiores rebanhos de suínos do mundo, mas somente despertou para a tecnologia de biodigestores, com vistas à produção de biogás, após a eclosão do primeiro "choque de petróleo" (BARRERA, 2003).

$O$ biodigestor é um equipamento onde a fermentação da matéria orgânica ocorre de modo controlado, proporcionando a redução do impacto ambiental e a geração de combustível de baixo custo. A fermentação dos resíduos ocorre através da ação de organismos microscópicos (bactérias). O processo de decomposição da matéria orgânica resulta na produção de biogás e restos digeridos sem cheiro (biofertilizante). $\mathrm{O}$ biodigestor é um equipamento muito utilizado para o tratamento de dejetos líquidos dos suínos, formado por um tanque revestido com pedra, alvenaria ou geomembrana de PVC e coberto com uma lona que possibilita a sua expansão para armazenar gazes (OLIVEIRA, 2004; INSTITUTO SADIA DE SUSTENTABILIDADE, 2006; DALMAZO; BAZI; OLIVEIRA, 2009; VIVAN et al., 2010).

O biodigestor é uma espécie de máquina viva, que precisa de acompanhamento contínuo para uma maximização do processo.

\subsection{BIOGÁS}

A digestão anaeróbia é um processo de tratamento de materiais orgânicos que se desenvolve na ausência de oxigênio e, simultaneamente, uma opção energética, com reconhecida vantagem ambiental. Um dos benefícios do processo, que logo contribuiu para um crescente interesse por esta tecnologia, reside na conversão da maior parte da carga poluente do efluente em uma fonte de energia: o biogás (OLIVEIRA, 2011).

O biogás proveniente da atividade dos microrganismos é composto por uma mistura de diversos gases, entre eles o metano, o dióxido de carbono, o hidrogênio e o dióxido de enxofre. O biogás é inflamável devido ao metano, gás mais leve 
que o ar, sem cor e odor. O que pode causar odor no biogás é o dióxido de enxofre, que mesmo em quantidades pequenas é perceptível pelo olfato e bastante corrosivo (OLIVEIRA, 2004).

Os microrganismos que atuam na ausência de oxigênio atacam a estrutura de materiais orgânicos complexos, produzindo compostos simples como o metano $\left(\mathrm{CH}_{4}\right)$ e o dióxido de carbono $\left(\mathrm{CO}_{2}\right)$ (SANCHEZ et al., 2005). A Figura 1 descreve a decomposição anaeróbia de compostos orgânicos; é apresentada como um processo de sete passos.

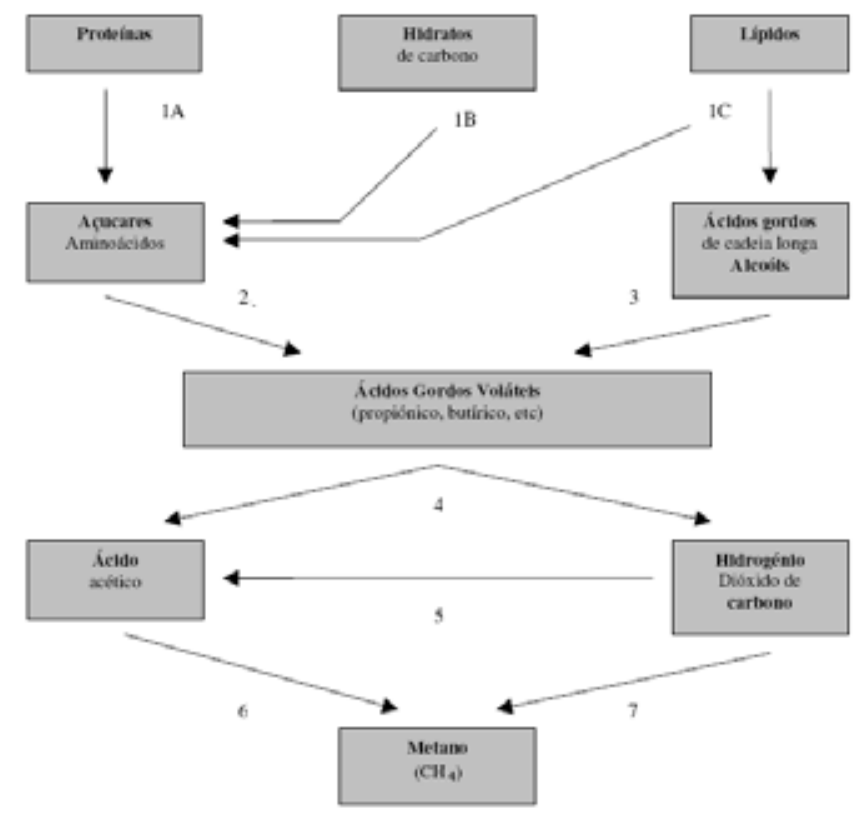

Figura 1. Digestão anaeróbica do material orgânico Fonte: Sanchez et al., 2005.

A composição típica do biogás é cerca de $60 \%$ de metano, 35\% de dióxido de carbono e 5\% de uma mistura de hidrogênio, nitrogênio, amônia, ácido sulfídrico, monóxido de carbono, aminas voláteis e oxigênio (SOUZA, 2001; WEREKO-BROBBY; HAGEN, 2000; ABBASI; TAUSEEF; ABBASI, 2012).

Para que ocorra a fermentação da matéria orgânica, essas bactérias precisam de um ambiente favorável para seu crescimento e desenvolvimento: ausência de 
compostos químicos tóxicos (sabão, detergente); temperatura adequada (entre $30^{\circ}$ e $45^{\circ} \mathrm{C}$ ); presença de matéria orgânica (dejetos); ausência de ar. Assim, se houver alguma interferência nesses fatores, poderá ser ocasionada uma redução na produção de biogás (SEIXAS; MARCHETTI, 1981; MARTINEZ et al., 2003; BITTON, 2005).

Os microrganismos produtores de metano são sensíveis à variação de temperatura, sendo recomendado assegurar-se a sua estabilidade, seja através do aquecimento interno ou pelo melhor isolamento térmico da câmara de digestão durante os meses de inverno. Este ponto é bastante crítico, pois nos meses de inverno é que se apresenta uma maior demanda por energia térmica e uma tendência dos biodigestores em produzirem volumes menores de biogás causados pelas baixas temperaturas (DALMAZO; BAZI; OLIVEIRA, 2009).

$\mathrm{O}$ gás metano pode ser usado como fonte de energia em vários tipos de equipamentos, como fogões, geradores, iluminação, aquecedores, na combustão em queimadores, ou usado como combustível para conjuntos motores/geradores para geração de energia elétrica, ou ainda, melhorada a qualidade do biogás (gás natural) pela remoção do dióxido de carbono e sulfureto de hidrogênio (TSAI; LIN, 2009). Estudos realizados pela Embrapa Suínos e Aves indicam que, em média, para cada 76 litros de dejetos líquidos de suíno, tem-se a formação de $1 \mathrm{~m}^{3}$ de biogás.

\subsection{BIOFERTILIZANTE}

A biomassa, depois de fermentada, deixa o interior do biodigestor em forma líquida, o chamado biofertilizante. Com grande quantidade de material orgânico, é excelente para a fertilização. Com a aplicação deste no solo, melhoram-se as qualidades biológicas, químicas e físicas do mesmo. Raslavi ius, Grzybek e Dubrovin (2011) salientam que a digestão anaeróbia aumenta o teor de NH4-N (Nitrogênio) e diminui o teor de carbono do estrume animal.

Sanchez et al. (2005) descrevem que o biofertilizante pode ser usado como adubo orgânico na agricultura, aquicultura e/ou como fertilizante foliar. $\mathrm{O}$ biofertilizante pode ser usado como adubo orgânico em conjunto com fertilizantes químicos em uma variedade de culturas de vegetais, proporcionando um rendimento comparável à obtida com o uso exclusivo de fertilizantes químicos, reduzindo o custo do processo de produção. 
O biofertilizante, ao contrário dos adubos químicos, melhora a qualidade do solo, deixando-o mais fácil de ser trabalhado e proporcionando uma melhor penetração de raízes. Além disso, faz com que o solo absorva melhor a umidade do subsolo, resistindo facilmente a longos períodos de estiagem. Sganzerla (1983, p. 25) descreve que:

O biofertilizante possui coloidais carregados negativamente, o que faz trocar por carga iônica, absorção superficial e coagulação. Seu poder de fixação dos sais é maior que das argilas, sendo responsável direto pela maior parte da nutrição das plantas, com até $58 \%$ da capacidade total de troca de bases do solo. Estabiliza os agregados de modo que resistam à ação desagregadora da água, absorvendo as chuvas mais rapidamente, evitando a erosão e conservando a terra por mais tempo.

O biofertilizante proporciona a multiplicação das bactérias, gerando mais vida e saúde ao solo e ocasionando aumento significativo na produtividade das lavouras. O mesmo autor ressalta ainda que os dejetos neste estágio (biofertilizante) encontram-se praticamente "curados" (na expressão do campo), pois não há possibilidade de nova fermentação; assim, não apresenta odor e, com isso, não atrai nenhum tipo de inseto.

A composição do biofertilizante pode variar de acordo com o tipo de biomassa utilizada no biodigestor. No caso dos dejetos de suínos, a composição do biofertilizante possui as seguintes concentrações: de 0,5 a 4,0\% de nitrogênio; de 0,5 a $5,0 \%$ de fósforo; 0,5 a 3,0\% de potássio e cerca de 90 a $95 \%$ de água (OLIVEIRA et al., 2011).

Dessa forma, o biofertilizante é um subproduto originado no processo de biodigestão, que proporciona ao máximo a utilização dos dejetos suínos, otimizando o processo de agregação de valor à propriedade rural.

\section{METODOLOGIA}

Segundo Calegare (2007) a realização de uma pesquisa é uma atividade básica e essencial para o desenvolvimento do conhecimento, pois através dele bus- 
cam-se novas informações, novas propostas e novas ações para o desenvolvimento socioeconômico-ambiental. A natureza deste trabalho, de acordo com o tema e os objetivos estabelecidos, caracteriza-se como uma pesquisa tipo exploratória e utiliza o método quantitativo e qualitativo de abordagem para a coleta e a análise dos dados junto às propriedades rurais.

A técnica trabalhada nessa pesquisa é o estudo de caso, pois se investigou um fenômeno dentro do seu contexto real, no qual as condições contextuais referem-se ao objeto que está sendo estudado. Ying (2005) comenta que a escolha da metodologia de estudo de caso deve-se ao fato de ser uma técnica de investigação de comportamentos que não podem ser manipulados isoladamente e devem ser analisados em conjunto.

$\mathrm{O}$ autor sugere ainda que seis fontes de evidência devem ser utilizadas, na medida do possível, para obter um bom estudo de caso, a saber: (1) documentação; (2) registros de arquivos; (3) entrevistas; (4) observações diretas; (5) observações participantes; e (6) artefatos físicos.

A documentação utilizada nesta pesquisa consistiu em relatórios apresentados pelos proprietários. Foram analisados arquivos como orçamentos das instalações. Os principais dados para o estudo foram coletados a partir de entrevistas semiestruturadas, que foram realizadas no local de estudo. Foram feitas observações diretas das diferentes atividades e processos no local do estudo, o que forneceu uma visão mais detalhada e segura do objeto de pesquisa. A base teórica para a pesquisa do estudo de caso foi de fontes bibliográficas nacionais e internacionais.

O campo de estudo desta pesquisa é a Microrregião de Santa Rosa, uma das microrregiões do Estado do Rio Grande do Sul, pertencente à Mesorregião Noroeste riograndense. A mesma é dividida em treze munícipios e a suinocultura tem uma história de sucesso nesta microrregião. No passado, chegou a ser uma das maiores produtoras de suínos do Rio Grande do Sul. Atualmente, vem retomando lugar de dianteira. Recentemente, teve um alto investimento na tecnologia de biodigestores, objeto de estudo deste trabalho. Foram analisadas na Microrregião de Santa Rosa todas as propriedades suinocultoras que possuíam biodigestores instalados, totalizando 30 (trinta) propriedades rurais. 


\section{DESENVOLVIMENTO E ANÁLISE DOS RESULTADOS}

Na Microrregião de Santa Rosa, a difusão da tecnologia de biodigestores se desenvolveu basicamente através de duas empresas privadas, ambas preocupadas e interessadas nas oportunidades de combate ao efeito estufa e à possibilidade de obtenção financeira pela venda de créditos de carbono. Estas desenvolveram parcerias com os produtores de suínos com o propósito de difusão da tecnologia. Apenas uma única propriedade começou seus investimentos nesta tecnologia com recursos próprios. Para uma melhor compreensão, analisou-se a inserção dessas empresas e os produtores envolvidos nos projetos de Mecanismos de Desenvolvimento Limpo na suinocultura.

Observa-se que o perfil das propriedades que possuem biodigestores instalados se dá basicamente por duas formas de sistema de produção da suinocultura: a maioria das propriedades $(93,33 \%)$ encontra-se em um regime de comodato (sistema de parceria), formalizado através de contratos que apresentam exigências quanto à origem da genética e da ração, especificações técnicas de manejo, medicamentos, provimento de assistência técnica e transporte. Os contratos apresentam garantias formais de compra e venda às agroindústrias vinculadas e especificações de volume e prazos, exigência de exclusividade, definição de um preço de referência e de critérios de remuneração em função do desempenho e uniformidade.

Por outro lado, uma minoria $(6,67 \%)$ trabalha em um sistema de produção independente e não possui contratos formalizados. Estão livres de exigências quanto à origem da genética e da ração e as vendas da produção são feitas aos frigoríficos de pequeno e médio porte da mesma região, que não possuem políticas de parceria definidas. A pesquisa demonstrou que essas propriedades de produção independente anteriormente estavam sob algum regime de comodato (sistema de parceria), abandonando-os devido às exigências de técnicas de manejo, que acabavam gerando muitos investimentos adicionais e, consequentemente, eliminando a possibilidade de renda/ucro com a atividade.

Verificou-se que $80 \%$ das propriedades são integradas a uma única empresa agroindustrial, com a qual comercilizam sua produção. Constatou-se que 93,33\% das propriedades rurais do objeto de estudo possuem biodigestores viabilizados por 
um programa de disseminação da tecnologia de biodigestores oriundo da agroindústria, que visa promover ações para o desenvolvimento sustentável no sistema de integração da suinocultura. Estas ações foram realizadas através do desenvolvimento de projetos com a intenção de geração de créditos de carbono, a partir da implantação de biodigestores nas granjas para tratamento dos dejetos gerados pelos suínos, bem como através da implantação de projetos ambientais e sociais. O custo dos biodigestores instalados seria pago com a venda dos créditos de carbono gerados. Após os custos abatidos, os valores referentes ao crédito de carbono seriam repassados aos produtores. Para a instalação dos equipamentos, foi firmado um contrato entre produtor (pessoa física) diretamente com a agroindústria. Dessa forma, mesmo que o produtor não tivesse mais vínculo da sua produção à com a agroindústria que realizou os investimentos, ainda assim possuiria vigente o contrato com o Programa em relação aos biodigestores implantados.

As propriedades restantes (6,67\%) realizaram a instalação dos equipamentos com empresa especializada na comercialização de créditos de carbono, sendo que a propriedade cedeu o espaço para construção do biodigestor e, por um período de 10 anos, a empresa reteria $90 \%$ das receitas do crédito de carbono e o agricultor recebia o restante $(10 \%)$, bem como biofertilizante para o seu uso. Além dessas, uma outra propriedade realizou investimentos nesta tecnologia com recursos próprios.

Constatou-se que 33,33\% dos biodigestores instalados na Microrregião de Santa Rosa encontram-se desativados, basicamente por desconhecimento de todos os processos que envolvem a biodigestão. Verificou-se que a falta de informação técnica por parte do suinocultor fez com que muitos equipamentos instalados fossem desativados, devido ao manejo inadequado, ocasionando a interrupção do funcionamento do equipamento.

A falta de informação técnica ocasionou um fator de desestímulo no uso dos biodigestores, uma vez que ocorre a falta de um aproveitamento sustentado dos produtos da biodigestão (biogás e biofertilizante) e também por uma dificuldade de condução do projeto por parte de uma das empresas investidoras na tecnologia. A pesquisa revela que os produtores não tiveram nenhum curso, palestra, visitas técnicas a outros empreendimentos, para a obtenção de informação a respeito da tecnologia de biodigestão, fato que se comprova que do total de propriedades com 
os biodigestores instalados, $66,67 \%$ responderam que possuem uma assistência técnica semestral, quando um técnico da empresa investidora visita a propriedade para conversar sobre o processo de biodigestão, tempo insuficiente para tratar de um processo que precisa de cuidados diários para um bom desempenho.

Os resultados são congruentes com o que descreve Palhares, Massoti e Souza (2008) em seu estudo, onde relata que a biodigestão no Brasil ainda caminha a passos lentos. Mesmo possuindo um dos maiores rebanhos de suínos e aves do mundo, o Brasil não possui mais do que alguns milhares de biodigestores, sendo que a maioria dos biodigestores foi desativada devido à falta de suporte técnico e de tecnologias eficientes. Verifica-se a necessidade de haver uma cooperação maior entre associações/cooperativas de suinocultores e técnicos dos programas de extensão rural, para que a implantação dos biodigestores obedeça a determinadas regras que padronizem sua utilização, evitando a frustração das expectativas dos criadores de suínos, levando-os a abandonar esta importante alternativa tecnológica.

Outro fator determinante para a disseminação dos biodigestores e, consequentemente, a manutenção dos equipamentos e o não aproveitamento nas propriedades dos subprodutos da biodigestão relatada pelos entrevistados, é a falta de recursos para investimento. Neste quesito, os bancos poderiam desempenhar um importante papel nesses projetos, disponibilizando linhas especiais de crédito via BNDES (Banco Nacional de Desenvolvimento Econômico e Social) ou Banco do Brasil, por exemplo, com prazos diferenciados, que pudessem oportunizar a viabilização de implantação e principalmente a manutenção dos equipamentos.

A possibilidade de os suinocultores poderem agregar à planilha de receitas da suinocultura a possibilidade de beneficiar-se dos custos ambientais, isto é, incentivos fiscais ou ambientais para quem venha a utilizar a tecnologia poderiam ser motivos alegados para a oferta de crédito. Percebe-se que, se o cuidado com o meio ambiente reverter em vantagens para o suinocultor, os criadores estariam mais propensos a continuar com o uso da tecnologia.

A tecnologia de biodigestores apresenta muitas vantagens aos produtores rurais; uma delas é a utilização da sobra dos dejetos após a passagem pelo biodigestor - o biofertilizante. Este resíduo pode ser utilizado como fertilizante para agricultura (normalmente, após uma etapa adicional de tratamento e tomando-se 
alguns cuidados), possuindo teores consideráveis de nitrogênio e fósforo, mas com uma probabilidade de disseminação de doenças reduzida.

Com a implantação em larga escala dos biodigestores e com o devido apoio técnico e cuidados na aplicação de biofertilizante, pode-se ter uma solução que favoreça a todos: o produtor se livra de um problema sério relacionado ao meio ambiente e ainda obtêm ganhos com isto (energia e fertilizante); o meio ambiente local, com uma poluição reduzida; e o ambiente global, com uma redução de emissões de gases.

O produtor pode reduzir custos ao economizar gás e/ou energia elétrica. Assim, além de evitar a poluição dos rios, o uso do biogás pode reduzir a demanda por gás de cozinha ou por energia elétrica. O efeito isolado sob o ponto de vista energético e de aquecimento global é pequeno, mas se um percentual grande de propriedades adotarem esta tecnologia, ele pode representar algo mais significativo.

Neste sentido, dentre as propriedades pesquisadas, uma iniciativa entre duas propriedades ganha destaque e merece ser apresentada, corroborando com o que salientam Bacenetti et al. (2013), de que a digestão anaeróbia de dejetos animais é uma maneira promissora de tecnificação do tratamento desses efluentes e possível de reduzir as emissões dos Gases do Efeito Estufa e demonstra como a biomassa é atraente como fonte alternativa de energia do ponto de vista da sustentabilidade, pois além do ganho explícito para o meio ambiente, há ganhos diretos e indiretos do ponto de vista social e tem se mostrado viável do ponto de vista econômico.

As propriedades citadas acima estão localizadas no município de Tucunduva. A propriedade "A" se configura como uma Unidade Produtora de Leitões - UPL $8 \mathrm{~kg}$, com um plantel de 400 matrizes e um volume diário de dejetos estimado em 18 metros cúbicos. Já a propriedade "B" se configura como uma Unidade Produtora de Leitões - UPL $23 \mathrm{~kg}$, com um plantel de 550 matrizes e um volume diário de dejetos estimado em 25 metros cúbicos.

Na Figura 2 pode-se visualizar a localização das propriedades, bem como a posição geográfica uma em relação à outra. 


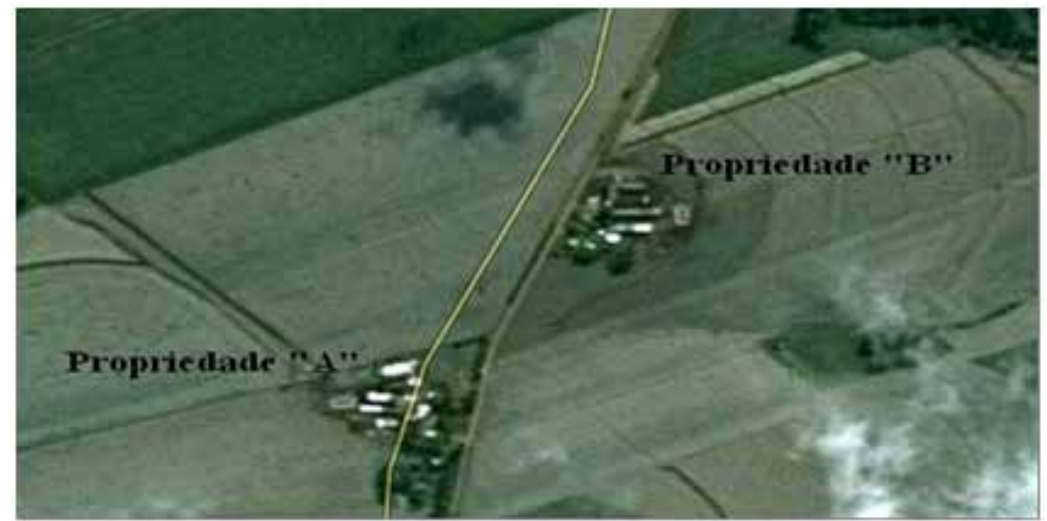

Figura 2. Visualização das propriedades Fonte: Google Earth (2011).

Ambas tiveram início de suas atividades na suinocultura em meados da década de 90. No ano de 2002 firmaram acordo com determinada agroindústria, em um sistema de parceria. No ano de 2004, a empresa criou o chamado Programa de Suinocultura Sustentável, ou Programa 3S. A meta era levar os pequenos e médios criadores em sistema de parceria ao sofisticado mercado de créditos de carbono e garantir uma importante fonte de receita para os suinocultores.

A concepção do projeto começou com a possibilidade de gerar créditos de carbono com as florestas de eucalipto da empresa, plantada para abastecer de biomassa o processo industrial de geração de vapor. Isto levou a agroindústria a iniciar, em 2003, estudos de Mecanismos de Desenvolvimento Limpo (MDL).

A conclusão foi de que o projeto mais promissor seria vinculado à suinocultura. Nas regiões com alta concentração de suínos, parte desses dejetos é lançada no solo e em cursos d'água, sem tratamento adequado.

Desta forma, o projeto de MDL previu a instalação de biodigestores e teve como objetivo estender a iniciativa a todos os suinocultores integrados da agroindústria; assim, produtores com propriedades de pequeno e médio porte teriam a oportunidade de acesso ao mercado de crédito de carbono.

O programa estabeleceu que o suinocultor receberia os aparelhos em regime de comodato e abateria o investimento com a geração de seus créditos de carbono, que seriam negociados pelo Instituto. O próprio modelo de biodigestor 
foi encomendado pela agroindústria a fornecedores nacionais, de forma a ter um custo acessível até para os menores produtores, aqueles que têm plantéis de até 300 animais nas granjas.

A agroindústria promoveu divulgação entre os suinocultores que tinham contrato em sistema de parceira, onde a adesão ao projeto era voluntária. O investimento dos produtores foi mínimo e de acordo com a viabilidade econômica de cada um. Da parte da agroindústria, obteve-se um financiamento de $\mathrm{R} \$ 60$ milhões aprovado pelo BNDES (Banco Nacional de Desenvolvimento Econômico e Social).

Deste contexto, as propriedades ("A" e "B") fizeram a adesão ao projeto e instalaram biodigestores em seus sistemas produtivos. Depois de instalados os equipamentos, por um período de tempo, o biogás gerado nos biodigestores era apenas queimado em Flaire (equipamento que faz a queima do biogás em altas temperaturas), para a creditação do crédito de carbono, e não era utilizado de outra forma na propriedade. Visualizando outras oportunidades, começaram os estudos por parte dos proprietários para viabilizar outras formas de aproveitamento do biogás, sem que houvesse interferência no projeto dos Mecanismos de Desenvolvimento Limpo (crédito de carbono).

Surge então, no decorrer do processo, a possibilidade de geração de energia isolada. A iniciativa de geração de energia elétrica a partir do biogás proveniente do tratamento dos dejetos suínos começou com a propriedade "A". Depois de muitos estudos, tanto de viabilidade técnica, bem como de viabilidade econômica, no mês de abril de 2010 , a propriedade adequou seus processos para a viabilização do projeto de geração de energia elétrica através do biogás.

Para um melhor entendimento, será detalhado passo a passo o processo de tratamento dos dejetos suínos até a fase de geração de energia elétrica isolada.

O terreno onde a propriedade "A" está localizada possibilitou a instalação do biodigestor e a implantação de unidades coletoras de dejetos de modo mais racional, facilitando as condições de manejo. O terreno está em certo grau de declive, possibilitando que os dejetos gerados na unidade produtiva sejam conduzidos em tubos de $150 \mathrm{~mm}$ (PVC), sem a necessidade de bombeamento, para uma caixa de homogeneização de vazão (conforme a Figura 3). Todo o dejeto produzido na propriedade é destinado para dentro do biodigestor, onde passa por um tempo de 
residência hidráulica estimado em 30 dias. O biodigestor construído na propriedade é do modelo canadense (conforme a Figura 4), de operação contínua e sua produção estimada de biogás corresponde a $150 \mathrm{~m}^{3}$ por dia, considerando-se uma vazão média de esgoto de $17 \mathrm{~m}^{3}$ de dejetos por dia.

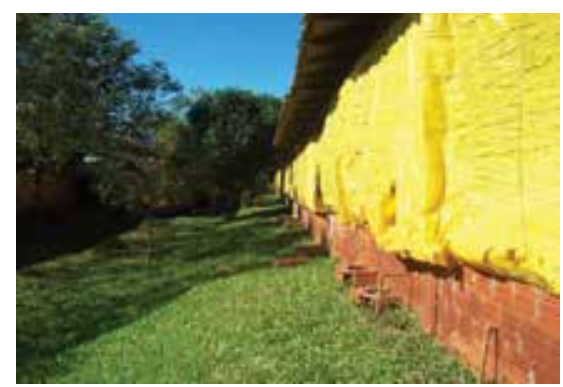

Figura 3. Tubulação coletora de dejeto Fonte: Dados da pesquisa.

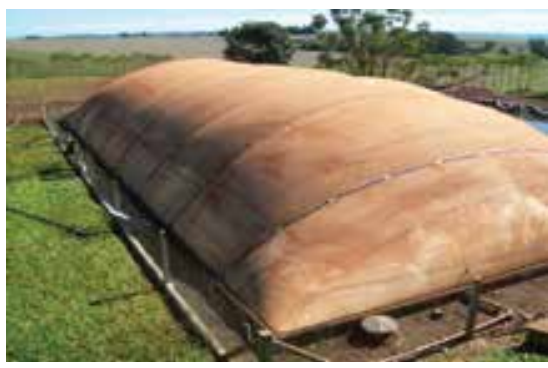

Figura 4. Biodigestor modelo canadense Fonte: Dados da pesquisa.

Além do próprio biodigestor, a propriedade instalou um sistema de armazenamento de biogás. Após o processo de biodigestão, o biogás é enviado para um balão de armazenamento, através de tubulação rígida de PVC com $50 \mathrm{~mm}$ de diâmetro (Figuras 5 e 6), para posteriormente ser usado como combustível no conjunto motor-gerador.

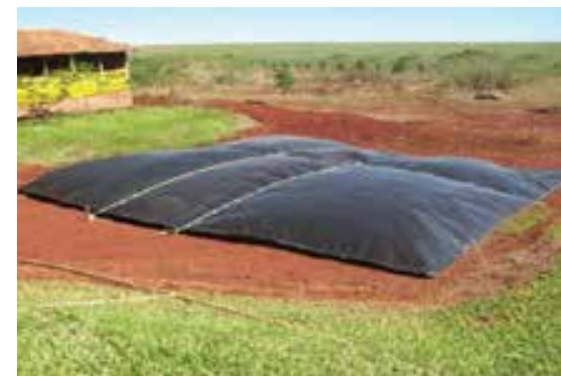

Figura 5. Balão de armazenamento Fonte: Dados da pesquisa.

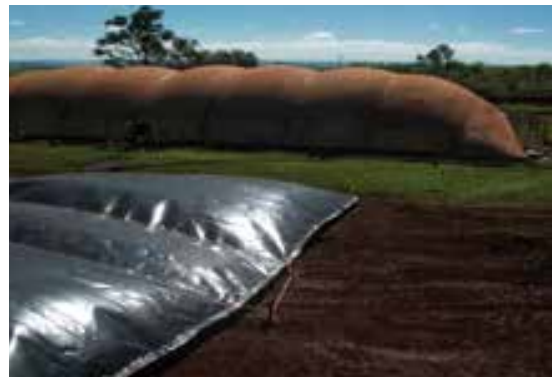

Figura 6. Balão de armazenamento Fonte: Dados da pesquisa.

Após o balão de armazenamento, o biogás é enviado através de tubulação até o conjunto motor-gerador instalado na propriedade, que consiste em um motor 
de combustão interna (diesel) adaptado para o uso do biogás como combustível, acoplado a um gerador de eletricidade, gerando energia dentro da propriedade com um sistema de distribuição interno e isolado, onde existe uma caixa de comando. Nesta caixa de comando, encontram-se a energia gerada pelo grupo gerador a biogás e a provinda da concessionária local, através do acionamento de uma chave central o proprietário criador escolhe qual energia utilizar.

O biogás armazenado é transportado por meio de tubulação rígida de PVC com $50 \mathrm{~mm}$ de diâmetro. Nessa tubulação existem um ou mais pontos de purga d'água. Na rede de distribuição do biogás para o conjunto gerador também foi instalado um sistema de filtro (Figura 7), com limalha de ferro no seu interior, visando à remoção de $\mathrm{H}_{2} \mathrm{~S}$.

O conjunto motor-gerador instalado (Figura 8) requer alguns cuidados, conforme recomendações para manutenção do sistema: troca de óleo e filtro a cada 250 horas. No total são 6 litros de óleo no momento da troca do filtro, pois é necessária sempre a troca deste. Troca das velas a cada 500 horas sendo que a cada 250 horas elas devem ser limpas. É necessário que a tensão da correia do alternador seja verificada semanalmente. A água do sistema de arrefecimento e o nível de óleo devem ser verificados diariamente.

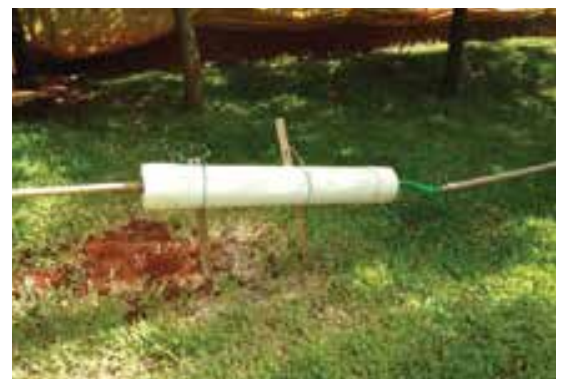

Figura 7. Filtragem do biogás Fonte: Dados da pesquisa.

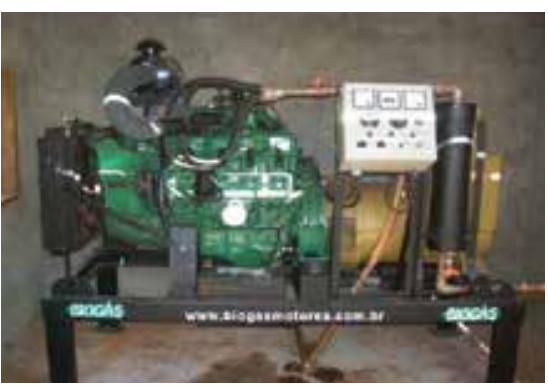

Figura 8. Conjunto motor-gerador Fonte: Dados da pesquisa.

Após o balão de armazenamento, o biogás é enviado através de tubulação até o conjunto motor-gerador instalado na propriedade, que consiste em um motor de combustão interna (diesel) adaptado para o uso do biogás como combustível, acoplado a um gerador de eletricidade, gerando energia dentro da propriedade com 
um sistema de distribuição interno e isolado, onde existe uma caixa de comando. Nesta caixa de comando, encontram-se a energia gerada pelo grupo gerador a biogás e a provinda da concessionária local, através do acionamento de uma chave central o proprietário criador escolhe qual energia utilizar.

O biogás armazenado é transportado por meio de tubulação rígida de PVC com $50 \mathrm{~mm}$ de diâmetro. Nessa tubulação existem um ou mais pontos de purga d'água. Na rede de distribuição do biogás para o conjunto gerador também foi instalado um sistema de filtro (Figura 7), com limalha de ferro no seu interior, visando à remoção de $\mathrm{H} 2 \mathrm{~S}$.

O conjunto motor-gerador instalado (Figura 8) requer alguns cuidados, conforme recomendações para manutenção do sistema: troca de óleo e filtro a cada 250 horas. No total são 6 litros de óleo no momento da troca do filtro, pois é necessária sempre a troca deste. Troca das velas a cada 500 horas sendo que a cada 250 horas elas devem ser limpas. É necessário que a tensão da correia do alternador seja verificada semanalmente. A água do sistema de arrefecimento e o nível de óleo devem ser verificados diariamente.

O conjunto motor-gerador foi instalado, na referida granja, no mês de abril de 2010, e funcionava por um período de 10 a 12 horas/dia. O consumo de biogás observado varia entre 10 e 15 metros cúbicos/hora no conjunto motor-gerador, dependendo da potência elétrica gerada.

Na entrada do biogás no conjunto motor-gerador existe um equipamento, para melhor identificação, que está na cor azul (Figura 9), onde ocorre a medição do biogás utilizado (consumido), para que posteriormente seja também contabilizado como crédito de carbono.

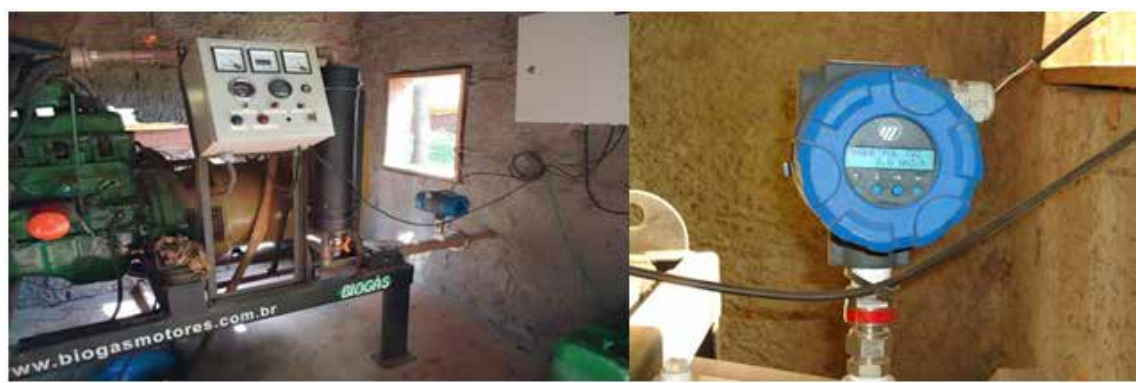

Figura 9. Sistema de medição metros cúbicos de biogás (crédito de carbono) Fonte: Dados da pesquisa. 
Salienta-se que a empresa que forneceu o conjunto motor-gerador teve que atender a critérios básicos de fornecimento de sistemas de aproveitamento energético de biogás para a geração de energia elétrica, estabelecidos através de um memorial do Centro de Inovação e Excelência da Agroindústria. A adequação do conjunto motor-gerador deve estar dentro dos requisitos da metodologia ONU (Organização das Nações Unidas) para a redução de emissões de gases, além de outras especificações obrigatórias fornecidas pela agroindústria, a fim de que o sistema de geração de energia seja aprovado e integrado ao sistema biodigestor/queimador do programa 3S.

A propriedade "B", como já relatado, também havia instalado o biodigestor apenas para fins de comercialização do crédito de carbono, onde um Flaire (queimador) fazia a queima do biogás. Como o gás estava sendo apenas queimado e não utilizado para outro fim, em comum acordo entre os proprietários iniciou-se conversas com a agroindústria, no ano de 2010, para conseguir viabilizar a possibilidade (autorização) de construção de um gasoduto interligando as duas propriedades; dessa forma, o gás da propriedade "B" seria transportado até a propriedade "A", onde estava instalado o conjunto motor-gerador (conforme Figura 10) e, da mesma forma, seriam contabilizados os metros cúbicos de biogás da propriedade "B" quando passassem pelo equipamento de medição (Figura 9).

Cabe salientar que toda a produção de energia elétrica gerada no projeto do condomínio de agroenergia é utilizada somente na propriedade que possui o conjunto motor-gerador, sendo que estão sendo realizadas negociações de como será eventual pagamento do biogás da propriedade "B”, entre outras decisões.

Desta forma, no mês de agosto de 2011, foi autorizada a construção. Sendo que, em setembro de 2011, foi construído o gasoduto interligando as propriedades "A" e "B" (Figura 11). A concepção do gasoduto foi realizada conforme modelo construído na Alemanha. O gasoduto possui 470 metros de distância entre as duas propriedades e o biogás é transportado por meio de tubulação rígida de PVC com $100 \mathrm{~mm}$ de diâmetro. 


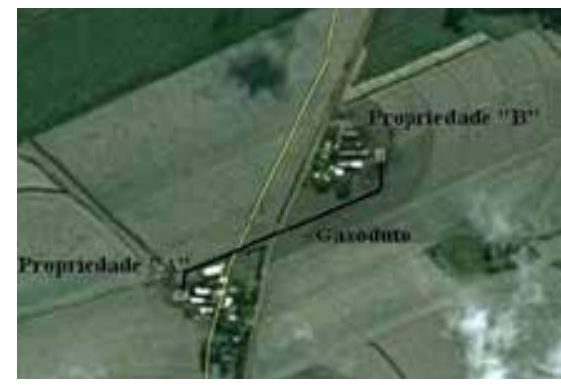

Figura 10. Visualização Projeto gasoduto de biogás

Fonte: Google Earth (2011).

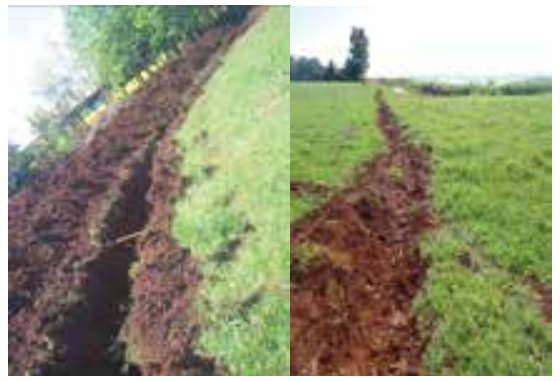

Figura 11. À esquerda: gasoduto sendo construído. À direita: gasoduto finalizado Fonte: Dados da pesquisa.

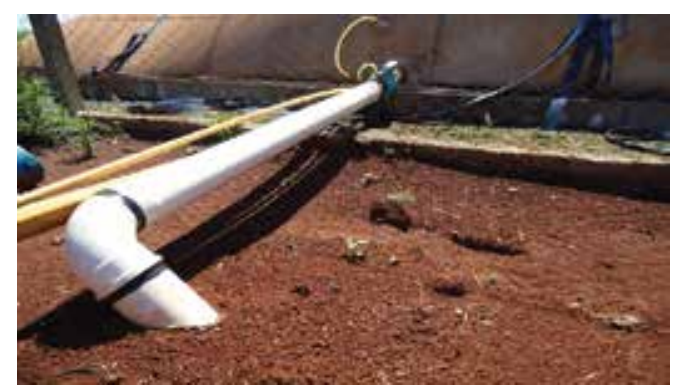

Figura 12. Gasoduto (propriedade "B") Fonte: Dados da pesquisa.

O gasoduto está interligado diretamente no biodigestor da propriedade "B", conforme visualizado na Figura 12, sendo que, após percorrer o gasoduto, o biogás é armazenado na propriedade "A" no balão de armazenamento (Figura 5).

Com a implantação dos projetos, chamaremos "Primeiro Projeto" quando a geração de energia elétrica contemplava apenas umas das propriedades como visto anteriormente e, de "Segundo Projeto", quando da construção do gasoduto, do condomínio de agroenergia.

Com o Primeiro Projeto finalizado, e o Segundo Projeto em andamento, é possível verificar números reais na produção de biogás e geração de energia elétrica. Vejamos alguns dados e resultado na tabela comparativa abaixo: 
Tabela 1. Dados comparativos

\begin{tabular}{lcc}
\hline & Primeiro Projeto & Segundo Projeto \\
\hline Produção de Biogás (mês) & $150 \mathrm{~m}^{3}$ & $350 \mathrm{~m}^{3}$ \\
\hline Geração de Energia Elétrica (mês) & $1700 \mathrm{KW} / \mathrm{h}$ & $5000 \mathrm{KW} / \mathrm{h}$ \\
\hline Tempo do Gerador em Operação & $10-12$ horas/dia & Aprox. 23 horas/dia \\
\hline Economia em R\$ Energia (mês) & $\mathrm{R} \$ 714,00$ & $\mathrm{R} \$ 2100,00$ \\
\hline
\end{tabular}

Fonte: Dados da pesquisa.

Um relatório comparativo de viabilidade econômico-financeira está sendo elaborado e será apresentado posteriormente em outro artigo/estudo. Os estudos de viabilidade econômico-financeira apresentam resultados animadores na utilização desta tecnologia, uma vez que se trata de uma Unidade de Produção de Leitões, que demanda grande consumo de energia para o aquecimento dos animais recémnascidos, além da possibilidade de uso do biofertilizante que reduz a quantidade necessária de adubo químico nas lavouras e também não foram abordados ainda possíveis ganhos com os créditos de carbono.

\section{CONCLUSÃO}

Com base no presente estudo, percebe-se a grande dificuldade encontrada para a disseminação dos biodigestores. Ainda não há a conscientização plena dos suinocultores de que a responsabilidade pelo manejo e destinação final de tais resíduos recai sobre eles e que, portanto, precisam usar alguma forma de tratamento eficiente destes resíduos, pois a não observância das leis a este respeito pode resultar na própria cassação do direito de exercer a atividade da suinocultura. A preocupação com as agressões ao meio ambiente está levando os órgãos governamentais e legislativos a criar punições cada vez mais pesadas contra os faltosos.

Verifica-se que a difusão da tecnologia dos biodigestores na região estudada enfrenta dificuldades relacionadas com a falta de um programa de formação de recursos humanos para dar apoio à sua implantação e manutenção e desenvolvimento de tecnologia alternativa. Os biodigestores rurais possuem uma má fama devido ao descrédito decorrente de erros de projeto, execução, operação e manutenção. 
Constatou-se que a possibilidade do uso do biogás nas propriedades suinocultoras agrega valor ao processo de tratamento dos dejetos das propriedades rurais, diminui os custos de produção e, inclusive, possibilita uma visão sistêmica do agronegócio, sob o ponto de vista da gestão ambiental. Salienta-se, entretanto, que esta tecnologia deva ser transferida aos produtores rurais com os devidos cuidados, sempre aprimorando a assistência técnica, para que erros, muitas vezes primários, não venham inviabilizar todo o processo.

O presente estudo também demonstrou a possibilidade de utilização do biogás para a geração de energia elétrica em um pequeno condomínio de agroenergia. Evidencia-se, através do estudo de caso, como a implantação de biodigestores para o tratamento dos dejetos, e a concomitante produção de biogás para a geração de energia e biofertilizante, em propriedades suinocultoras, podem melhorar a qualidade e a produtividade de propriedades criadoras de suínos, contribuindo na solução de problemas relacionados principalmente à questão ambiental e de disponibilidade de energia, além de incentivar a permanência do trabalhador no meio rural, através de uma produção sustentável.

\section{REFERÊNCIAS}

ABBASI, T.; TAUSEEF, S.M.; ABBASI, S.A. Anaerobic digestion for global warming control and energy generation-An overview. Renewable and Sustainable Energy Reviews, v. 16, n. 5, p. 3228-3242, 2012.

BACENETTI, J. et al. Anaerobic digestion of different feedstocks: Impact on energetic and environmental balances of biogas process. Science of The Total Environment, v. 463-464, n. 0, p. 541-551, 2013.

BARICHELLO, R.; HOFFMANN, R. O uso de Biodigestores em Pequenas e Médias Propriedades Rurais com ênfase na agregação de valor: um estudo de caso da Região Noroeste do Rio Grande do Sul, 2010. 139f. Dissertação (Especialização em Engenharia de Produção) - Universidade Federal de Santa Maria, 2010.

BARRERA, P. Biodigestores: energia, fertilidade e saneamento para zona rural. São Paulo: Ícone, 2003. 106p. 
BITTON, G. Wastewater microbiology. 3. ed., New York: Willey Liss Inc., 2005. $763 \mathrm{p}$.

CALEGARE, L. Proposta de um modelo de gestão de resíduos de serviços de saúde para os hospitais da Quarta Colônia/RS. 2007. Dissertação (Mestrado em Engenharia de Produção) - Universidade Federal de Santa Maria, Santa Maria, 2007.

DALMAZO, G.S.; BAZI, S.M.; OLIVEIRA, P.A.V. de. Biodigestores. In: MIRANDA, C.R. de (Org). Dia de Campo: suinocultura e meio ambiente: termo de ajuste de condutas da suinocultura. Concórdia: Embrapa Suínos e Aves, 2009.

EMBRAPA. Aspectos práticos do manejo de dejetos suínos. Florianópolis, 1995.

EPAGRI. Aspectos práticos do manejo de dejeto suínos. Florianópolis: EPAGRI/ EMBRAPA - CNPSA, 1995.

HOLM-NIELSEN, J.B.; AL SEADI, T.; OLESKOWICZ-POPIEL, P. The future of anaerobic digestion and biogas utilization. Bioresource technology, v. 100, n. 22, p. 5478-5484, 2009.

MARTINEZ, J.; GUIZIOU, F.; PEU, P.; GUEUTIER, V. Influence of treatment techniques for pig slurry on methane emissions during subsequent storage. Biosystems Engineering, v. 85, n. 3, p. 347-354, 2003.

OLIVEIRA, P.A.V de. Tecnologias para o manejo de resíduos na produção de suínos: manual de boas práticas. Concórdia: Embrapa Suínos e Aves, 2004. 109p. (Programa Nacional do Meio Ambiente - PNMA II).

OLIVEIRA, S.V. et al. Generation of bioenergy and biofertilizer on a sustainable rural property. Biomass and bioenergy, v. 35, n. 7, p. 2608-2618, 2011.

PALHARES, J.C.P.; MASSOTI, Z.; SOUZA, L.D. Biodigestor modelo indiano: análise da transferência da tecnologia com base no perfil ambiental, produtivo e social. Boletim de Pesquisa e Desenvolvimento, Concórdia, n. 3, p. 1-24, 2008.

RASLAVIČIUS, L.; GRZYBEK, A.; DUBROVIN, V. Bioenergy in Ukraine-Possibilities of rural development and opportunities for local communities. Energy Policy, v. 39, n. 6, p. 3370-3379, 2011. 
INSTITUTO SADIA DE SUSTENTABILIDADE. Manual de Operação de Biodigestores. [s.l.;s.n.], 2006. (Cartilha).

SANCHEZ, E.; BORJA, R.; TRAVIESO, L.; MARTIN, A.; COLMENAREJO, M.F. Effect of organic loading rate on the stability, operational parameters and performance of a secondary upflow anaerobic sludge bed reactor treating piggery waste. Bioresource Technology, v. 96, p. 335-344, 2005.

SEIXAS, J.; MARCHETTI, D.A.B. Construção e funcionamento de biodigestores. Brasília: Embrapa Suínos e Aves, 1981. 60p.

SGANZERLA, E. Biodigestores: uma solução. Porto Alegre: Agropecuária, 1983.

SOUZA, C.F. Biodigestão anaeróbia de dejetos de suínos: obtenção de dados e aplicação no desenvolvimento de um modelo dinâmico de simulação da produção de biogás. 2001. 140f. Tese (Doutorado em Zootecnia) - Universidade Estadual Paulista, Jaboticabal, 2001.

TSAI, W.T.; LIN, C.I. Overview analysis of bioenergy from livestock manure management in Taiwan. Renewable and Sustainable Energy Reviews, v. 13, n. 9, p. 2682-2688, 2009.

VIVAN, M.; KUNZ, A.; STOLBERG, J.; PERDOMO, C.C.; TECHIO, V.H. Eficiência da interação biodigestor e lagoas de estabilização. Revista Brasileira de Engenharia Agrícola e Ambiental, v. 14, p. 320-325, 2010.

WEREKO-BROBBY, C.Y.; HAGEN, E.B. Biomass conversion and technology. New York: John Wiley \& Sons. 2000. p. 2-224.

YING, R. Estudo de caso: planejamento e métodos. Porto Alegre: Bookman, 2005.

Recebido em: 30 de setembro de 2013 Aceito em: 21 de maio de 2014 